\title{
Left Ventricular Diverticulum in Two Adult Patients
}

\author{
Mustafa YAZICI, ${ }^{1} \mathrm{MD}$, Sabri Demircan, ${ }^{1} \mathrm{MD}$, Kenan Durna, ${ }^{1} \mathrm{MD}$, \\ and Erdogan YASAR, ${ }^{1} \mathrm{TcH}$
}

\begin{abstract}
SUMMARY
Left ventricular diverticulum is a rare congenital anomaly. In the adult population, the incidence was reported to be $0.26 \%$ in nonselected patients who underwent cardiac catheterization. Diverticula are usually localized near the apex and most often involve the inferior or anterior parietal walls of the left ventricle. In this report, two cases with congenital left ventricular diverticulum are presented, and the pathophysiologic, diagnostic, and therapeutic approaches of this cardiac malformation are discussed. (Int Heart J 2005; 46: 161-165)
\end{abstract}

Key words: Left ventricular diverticulum, Echocardiography, Angina, Angiography

LEFT ventricular diverticulum is a rare congenital anomaly. In the adult population, the incidence was reported to be about $0.4 \%$ in an autopsy series of patients with cardiac death, and about $0.26 \%$ in nonselected patients who underwent cardiac catheterization. ${ }^{1,2)}$ Diverticula are usually localized near the apex and most often involve the inferior or anterior parietal walls of the left ventricle. ${ }^{3)}$ They can be associated with midline defects concerning the pericardium, and malformations such as septal defects, ${ }^{4)}$ pulmonary stenosis or dextrocardia. ${ }^{5}$ We report two cases of isolated congenital left ventricular diverticulum with complaints of concomitant chest pain.

\section{CASe 1}

A 55-year-old male patient was referred to our clinic because of complaints of chest pain during effort. There were no coronary risk factors except smoking (20 years) and age. His blood pressure was $135 / 80 \mathrm{mmHg}$ and he had a regular pulse of 84 beats/min. No heart murmur was detected and his lungs were clear. An abdominal examination was unremarkable and edema was absent. No abnormal neurological findings were noted, and the results of laboratory tests and chest $\mathrm{X}$-rays were unremarkable. An electrocardiogram (ECG) showed a sinus rate of

From the ${ }^{1}$ Department of Cardiology, Ondokuz Mayis University Medical School, Samsun, Turkey.

Address for correspondence: Mustafa Yazici, MD, Department of Cardiology, Ondokuz Mayis University Medical School, Kurupelit 55139, Samsun, Turkey.

Received for publication June 30, 2004.

Revised and accepted September 6, 2004. 
80 beats/min with ST-T abnormalities in precordial derivations. Echocardiographic (ECHO) examination revealed normal left ventricular function (ejection fraction; 63\%), internal diameters, and wall motions. Two dimensional echocardiography demonstrated diverticula at the inferior wall in the apical two chamber view (Figure 1). Coronary angiography showed $50 \%$ stenosis at the midportion of the left circumflex $(\mathrm{Cx})$ coronary artery. However, there were no atherosclerotic lesions at the left anterior descending (LAD) artery or right coronary artery (RCA). Left ventriculography in the right anterior oblique view revealed a contractile diverticulum at the inferior wall of the left ventricle (Figure 2). Maximal treadmill exercise testing was performed to investigate ischemia, however, nei-
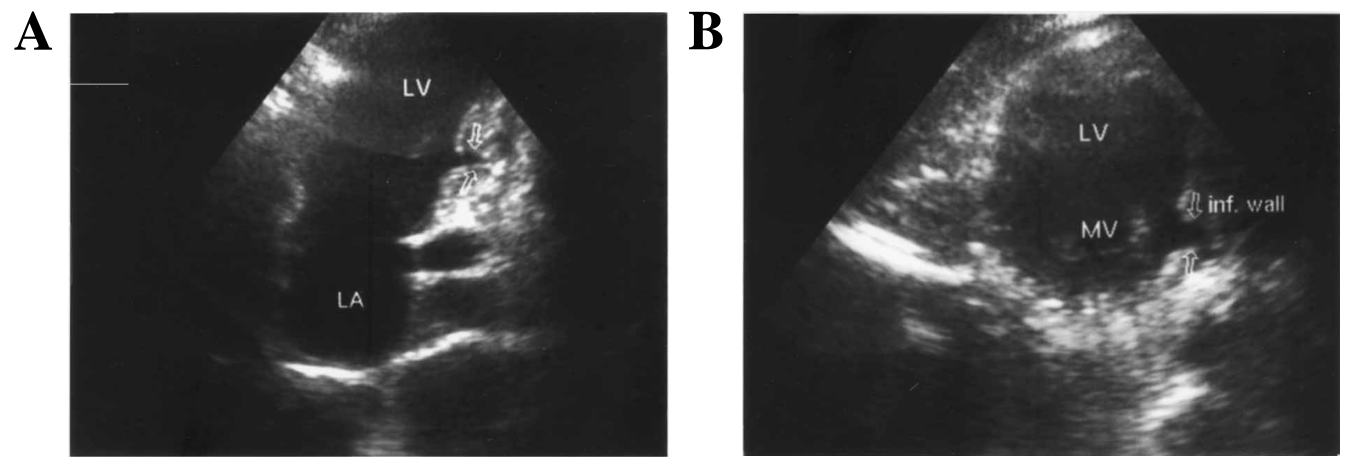

Figure 1. Echocardiography. ( $L V=$ left ventricle; $L A=$ left atrium; inf = inferior) A: Apical two chamber view. B: Modified apical two chamber view.

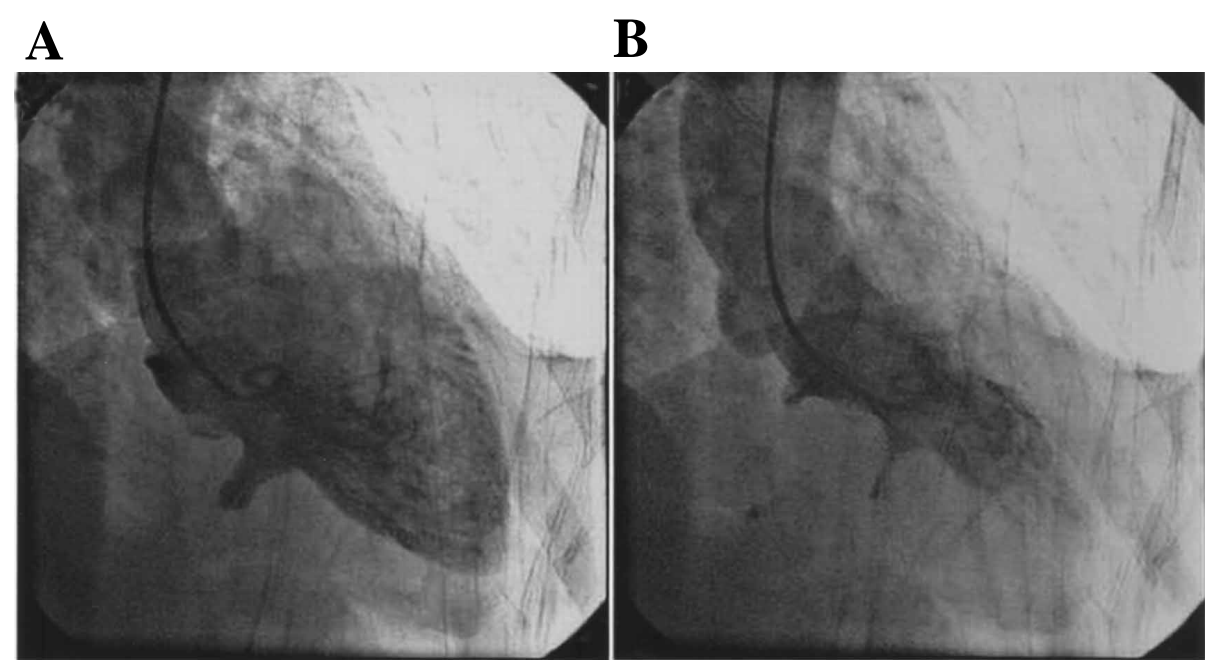

Figure 2 Left ventriculography of first case. Right anterior oblique view. A: Diastole. B: Systole. 
ther ST depression nor angina were seen. Medical therapy including aspirin, beta blocker, and statin was given and then the patient was discharged.

\section{CASE 2}

A 63-year-old male patient was admitted to our emergency department due to complaints of chest pain at rest. There were no coronary risk factors except smoking (20 years) and age. His blood pressure was $120 / 75 \mathrm{mmHg}$ and he had a regular pulse of 72 beats/min. No heart murmur was detected and his lungs were clear. An abdominal examination was unremarkable and edema was absent. No abnormal neurological findings were noted. An ECG showed a sinus rate of 80 beats/min with ST-T abnormalities in precordial derivations. The results of laboratory tests were unremarkable except for a slight troponin increase (cTn-I $=0.22$ $\mathrm{ng} / \mathrm{mL}$ ). The patient was hospitalized with a diagnosis of unstable angina pectoris and aspirin, beta blocker, heparin, clopidogrel, and a statin were administered. ECHO examination revealed normal left ventricular function (ejection fraction; $56 \%$ ) and wall motions. Coronary angiography showed $70 \%$ stenosis at the obtuse margin 2 (OM2) of the left $\mathrm{Cx}$ coronary artery. However, there were no atherosclerotic lesions at the left LAD or RCA. Left ventriculography in the right anterior oblique view revealed multiple contractile diverticula at the inferobasal wall of the left ventricle (Figure 3). A stent was implanted for the lesion at the OM2. The medications mentioned above were administered, and the patient was discharged.

A

B

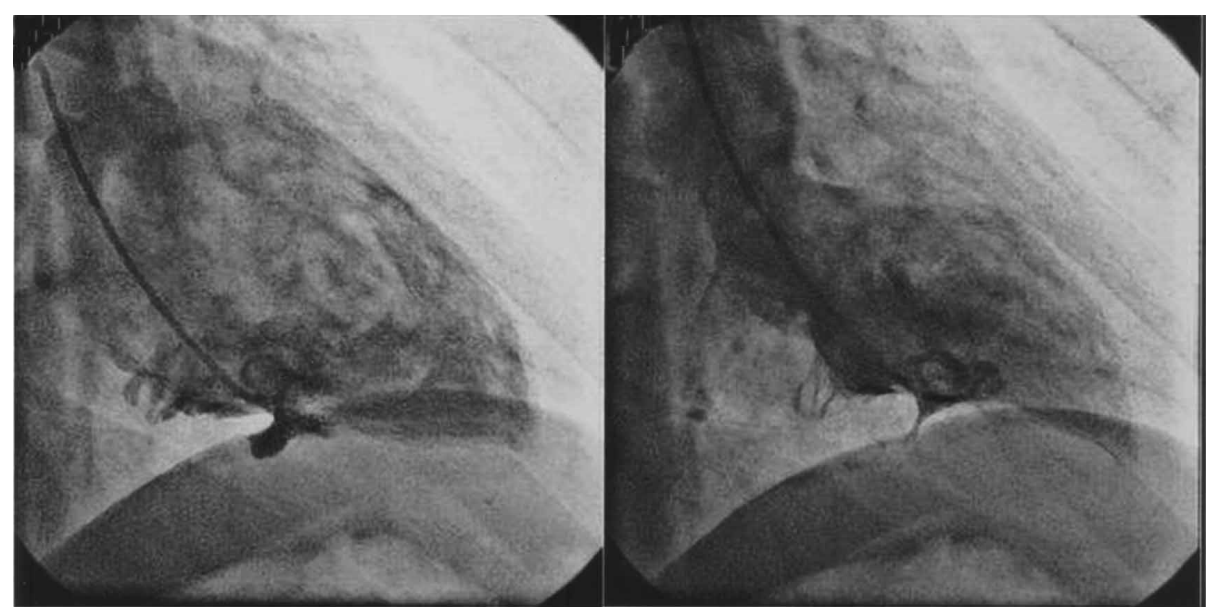

Figure 3. Left ventriculography of second case. Right anterior oblique view.

A: Diastole. B: Systole. 


\section{DISCUSSION}

A congenital left ventricular diverticulum is a rare cardiac malformation consisting of a localized protrusion of endocardium and myocardium from the free wall of the left ventricle. It was initially described in $1838 .{ }^{6)}$ Possible etiologies of left ventricular diverticulum include intrinsic abnormalities during embryogenesis or acquired malformations in utero, including coronary artery abnormalities, viral infections, or arrhythmia-related vascular accidents. ${ }^{7)}$ Congenital heart diverticula have been classified in fibrous and muscular tissue. ${ }^{8)}$ The fibrous type arises either in the apical or subvalvular area, exhibits a narrow connection, and often causes mitral or aortic incompetence. Muscular diverticula are localized near the apex and most often involve the inferior or anterior parietal walls of the left ventricle. ${ }^{3,9)}$ Rarely, it may be multiple (diverticulosis), such as in our second case. ${ }^{8)}$

Cardiac diverticula are often clinically silent, but they may be associated with serious complications such as systemic embolisms, severe ventricular arrhythmias, heart failure, cardiac rupture, and sudden death. ${ }^{710)}$ Admitted with chest pain and ECG abnormalities were the clinical characteristics of our cases.

Chest pain and ECG abnormalities in our second case might be related to coronary disease. However, we were unable to explain the causes of similar findings in the first case. The ECG abnormalities observed in the first patient might reflect repolarization abnormalities. In addition, this angina accompanied by ECG abnormalities may have been a result of transient ischemia due to diverticulum which was not induced by exercise testing.

All muscular diverticula cases reported previously were under 30 years of age. Of these patients, there were small number of cases with ECG abnormalities and chest pain, and associated ECG abnormalities were nonspecific in all. For example, Brachlow, et $a l^{7)}$ reported a prenatal diverticulum patient who had $\mathrm{T}$ wave inversion on precordial derivations with normal coronary arteries. Tsujimoto, et $a l^{11)}$ reported that hydrops, hydropericardium, and myocardial infarction were present in 8 of 14 symptomatic perinatal cases.

ECHO can detect large left ventricular diverticula, but it is difficult to detect a small one by the conventional 2-D method. In this situation, harmonic imaging may be useful. ${ }^{8,12)}$ In our first case, the diverticulum could be determined by conventional 2-D ECHO. Left ventriculography is more useful than magnetic resonance imaging or echocardiography for detecting this anomaly. ${ }^{13)}$

Diverticulum is often clinically difficult to distinguish from a congenital left ventricular aneurysm. Important diagnostic aspects are the narrow connection with the main chamber and/or the presence of ejection flow from the diverticulum to the ventricle. ${ }^{14)}$ Surgery may be considered in symptomatic patients or in those believed to be at high risk for rupture. ${ }^{15}$ ) 
We treated the patients medically because their diverticula were small and had no risk of rupture. Aspirin, beta blocker, and statin were given in one case due to atherosclerotic plaques and PTCA. Aspirin will also be useful in preventing thrombus formation in diverticula. On the other hand, beta blockers prevent myocardial ischemia which may be due to contractile diverticula.

\section{REFERENCES}

1. Skapinker S. Diverticulum of the left ventricle of the heart; review of the literature and report of a successful removal of the diverticulum. Arch Surg 1951; 63: 629-34.

2. Walton-Shirley M, Smith SM, Talley JD. Left ventricular diverticulum: case report and review of the literature. Cathet Cardiovasc Diagn 1992; 26: 31-3.

3. Baratella MC, Menti L, Daliento L. Congenital left ventricular diverticulum. Int J Cardiol 1997; 59: 93-5.

4. Yamashita H, Momomura S, Mochizuki T, Suzuki J, Takenaka K, Serizawa T. Congenital left ventricular diverticulum with ventricular septal defect, mitral and tricuspid regurgitation, and coronary disease. Am Heart J 1993; 126: 461-3.

5. Mady C. Left ventricular diverticulum: analysis of two operated cases and review of the literature. Angiology 1982; 33: 280-6.

6. O'Bryan. In: Peacock TB, editor. On Malformations of the Human Heart. 2nd ed. London, UK: Churchill \& Sons, 1866.

7. Brachlow A, Sable C, Smith S, Slack M, Martin G. Fetal diagnosis and postnatal follow-up of an asymptomatic congenital left ventricular diverticulum. Pediatr Cardiol 2002; 23: 658-60.

8. Takahashi M, Nishikimi T, Tamano K, et al. Multiple left ventricular diverticula detected by second harmonic imaging: a case report. Circ J 2003; 67: 972-4.

9. Huang G, Pavan D, Antonini-Canterin F, Piazza R, Burelli C, Nicolosi GL. Asymptomatic isolated congenital left ventricular muscular diverticulum in an adult: a case report. Echocardiography 2003; 20: 191-5.

10. Yoshida T, Niwano S, Izumi T. Images in cardiology: Arrhythmogenic giant submitral left ventricular diverticulum. Heart 2002; 88: 52.

11. Tsujimoto H, Takeshita S, Kawamura Y, Nakatani K, Sato M. Isolated congenital left ventricular diverticulum with perinatal dysrhythmia: a case report and review of the literature. Pediatr Cardiol 2000; 21: 175-9. (Review)

12. Ueda T, Mizushige K, Yukiiri K, et al. Contrast harmonic power Doppler imaging of congenital ventricular diverticulum: a case report. Angiology 2001; 52: 357-9.

13. Holeman A, Bellorini M, Lefevre T, et al. Isolated left ventricular muscular diverticulum in an adult. Value of non-invasive examinations. Arch Mal Coeur Vaiss 1997; 90: 1433-6. (Review) (French)

14. Teske DW, McGovern JJ, Allen HD. Congenital fibrous left ventricular diverticulum. Am Heart J 1993; 126: 1233-5.

15. Westaby S, Katsumata T, Runciman M, Burch M. Ruptured left ventricular diverticulum in infancy. Ann Thorac Surg 1997; 64: 1181-2. 